\title{
Food intake and nutrition knowledge in severely obese pregnant women in Scotland
}

\author{
N. A. Mohd-Shukri, S. Forbes, F. C. Denison, J. E. Norman, B. R. Walker and R. M. Reynolds \\ Tommy's Centre for Maternal and Fetal Health, Queen's Medical Research Institute, University of Edinburgh, \\ Edinburgh EH16 4TJ, UK
}

In a recent survey, $24.1 \%$ of Scottish women were classified as obese and $3.5 \%$ as severely obese ${ }^{(1)}$. Maternal obesity has short- and longterm detrimental effects on mothers' and babies' health ${ }^{(2)}$. However, evidence is limited for best diet and gestational weight management advice for severely obese women. We aimed at assessing food intake and knowledge in severely obese (BMI $\left.>40 \mathrm{~kg} / \mathrm{m}^{2}\right)$ and lean $(\mathrm{BMI}$ $20-25 \mathrm{~kg} / \mathrm{m}^{2}$ ) pregnant women.

One hundred and two severely obese and fifty lean (BMI $\left.43.5(0.5) v .22 .6(0.2) \mathrm{kg} / \mathrm{m}^{2}, P<0.001\right)$ pregnant women were recruited from a cohort study of severe obesity in pregnancy at Royal Infirmary, Edinburgh, UK. Ethical approval and written informed consent were obtained. Obese women were advised about healthy eating and weight maintenance during pregnancy. Food intake (total energies, macroand micronutrients) was assessed during early (12-20 weeks gestation) and late (28-36 weeks) pregnancy by validated FFQ ${ }^{(3)}$. Thirty-two women from each group completed a food diary for $4 \mathrm{~d}$ ( 3 week days and 1 weekend day). A subgroup completed the General Nutrition Knowledge Questionnaire $^{(4)}$ ( $n 69$ obese, $n 47$ lean) and a Nutrition Appetite Questionnaire ${ }^{(5)}$ ( $n 37$ obese, $n 29$ lean). Serial anthropometry was performed. Data were analysed using SPSS version 14.0. Data are mean (SEM).

Obese women gained significantly less weight than lean women $(6.09(0.54) v .10 .56(0.65) \mathrm{kg}, P<0.001)$ between booking and 36 weeks gestation. Total energy intake was higher in obese compared with lean during early pregnancy ((11422.32 (548.104) v. 9886.792 $(548.104) \mathrm{kJ} / \mathrm{d})(2730(131) v .2363(95) \mathrm{kcal} / \mathrm{d}), P<0.05)$ but not different during late pregnancy $((9840.768(389.112) v .10334 .48$ $(510.448) \mathrm{kJ} / \mathrm{d})(2352(93) v .2470(122) \mathrm{kcal} / \mathrm{d}), P=N S)$. Obese women reported proportionally higher intake of sugars, saturated fat, dietary cholesterol but lower fibre, folic acid, $\mathrm{Fe}, \mathrm{Ca}$ and vitamin $\mathrm{D}(P<0.05)$ than lean in both early and late pregnancy. Both groups failed to meet recommended values for key nutrients in pregnancy including $\mathrm{Ca}, \mathrm{Fe}$, folic acid and vitamin D. Both groups reported significantly lower intake of total energy by food diary compared with FFQ (obese: $6698.584(347.272) v .10489 .288$ (711.28) kJ/d; lean: $7313.632(271.96) v .10727 .776(514.632) \mathrm{kJ} / \mathrm{d}$ ) (obese: 1601 (83) v. 2,507 (170) kcal/d; lean: $1748(65) v .2564(123) \mathrm{kcal} / \mathrm{d})$ and this pattern was similar with all other nutrients (range $23-85 \%$ lower, depending on nutrient, all $P<0.05$ ). Obese women reported lower appetite than lean in both early $(20.9(0.5) v .23 .0(0.5), P<0.01)$ and late $(20.8(0.6) v .23 .4(0.4) P<0.01)$ pregnancy. Obese women also had lower scores in general nutrition knowledge $67(1.9) v .80(1.7)$ marks, $P<0.05)$ than the lean group. Results remained significant after controlling for the education level.

In summary, severely obese pregnant women had significantly less gestational weight gain than lean. It is not known whether this is due to the reduction in energy intake during pregnancy, the reported lower appetite, or due to the dietary advice given and the intense care and attention they received during participation in the study. Severely obese pregnant women ate a more unhealthy diet, rich in saturated fats and sugars and had lower scores in general nutrition knowledge. Both groups reported lower energy intake in the food diary compared with FFQ responses, suggesting the possibility of under-reporting. The failure to meet recommendations for key nutrients in pregnancy in both groups suggests dietary education is necessary among women planning pregnancy.

This work was supported by Tommy's and the Malaysian Ministry of Higher Education.

1. Gray L \& Leyland A (2009) Scottish Health Survey. The Scottish Government.

2. Davies GA, Maxwell C, McLeod L et al. (2010). J Obstet Gynaecol Can 32(2), 165-173.

3. Scottish Collaborative Group (2008) Food Frequency Questionnaire version 6.6. University of Aberdeen, UK.

4. Parmenter K \& Wardle J (1999) Eur J Clin Nutr 53(4), 298-308.

5. Wilson MM, Thomas DR, Rubenstein LZ et al. (2005) Am J Clin Nutr 82(5), 1074-1081. 